\title{
A reforma do ensino médio Regressão de direitos sociais
}

\section{Dante Henrique Moura* Domingos Leite Lima Filho}

\begin{abstract}
RESUMO: No artigo, analisamos as relações entre o ensino médio e a educação profissional técnica de nível médio (EPTNM) face à reforma tratada na Lei 13.415/2017. Concluímos que a Lei integra uma racionalidade voltada a reconfigurar o Estado brasileiro em direção a uma nova fase de regressão social. Sobre a EPTNM, concluímos que a reforma sinaliza para o fortalecimento da dualidade educacional e de uma orientação mercadológica; precarização da docência.
\end{abstract}

Palavras-chave: Ensino médio. Educação profissional técnica de nível médio. Reforma do ensino médio. Regressão social. Reconfiguração de Estado.

\section{High school reform}

Regression of social rights

\begin{abstract}
In the article, we analyzed the relationships between high school and technical professional education at the secondary level (EPTNM) in light of the reform enshrined in Law no. 13.415/2017. We conclude that the law integrates a rationality aimed at reconfiguring the Brazilian State to move towards a new phase of social regression. Regarding the EPTNM, we conclude that the re-
\end{abstract}

* É doutor em Educação pela Universidade Complutense de Madri e professor do Instituto Federal de Educação, Ciência e Tecnologia do Rio Grande do Norte (IFRN). É um dos fundadores do Núcleo de Pesquisa em Educação (NUPED) do IFRN, sendo atualmente seu coordenador. Atualmente integra o Comitê Científico da ANPEd, representando o GT09 (Trabalho e Educação) e coordena o FORPRED Nordeste. Natal/ RN - Brasil. E-mail:<dante.moura@ifrn.edu.br>.

* Doutor em Educação na Universidade Federal de Santa Catarina e Pós-Doutorado na Facultad de Ciencias Sociales da Universidad de Salamanca. É professor do programa de Pós-Graduação em Tecnologia e Sociedade da Universidade Tecnológica Federal do Paraná e coordenador do doutorado interinstitucional DINTER PPGTE/UTFPR-UFPI. Curitiba/PR - Brasil. E-mail:<domingos@utfpr.edu.br>. 
form signals the strengthening of educational duality and a market based orientation. It leads to a precariousness in teaching.

Keywords: High school. Professional secondary technical education. High school reform. Social regression. State reconfiguration.

\section{La reforma de la enseñanza media:}

Regresión de derechos sociales

RESUMEN: En el artículo, analizamos las relaciones entre la enseñanza media y la educación profesional técnica de nivel medio (EPTNM) a la luz de la reforma tratada en la Ley 13.415/2017. La conclusión es que la Ley forma parte de una racionalidad orientada a reconfigurar el Estado brasileño hacia una nueva fase de regresión social. Sobre la EPTNM, nuestra conclusión es que la reforma conlleva el fortalecimiento de la dualidad educativa y de una orientación mercadológica; precarización de la docencia.

Palabras clave: Enseñanza media. Educación profesional técnica de nivel medio. Reforma de la enseñanza media. Regresión social. Reconfiguración del Estado.

\section{La réforme de l'enseignement secondaire: Recul des droits sociaux}

RÉSUMÉ: Dans cet article, nous étudions les relations entre l'enseignement secondaire et l'éducation professionnelle technique de niveau secondaire (EPTNM) face à la réforme traitée dans la Loi 13.415/2017. Nous en concluons que la Loi instaure une rationalité de reconfiguration de l'état Brésilien dans le sens d'une nouvelle phase de recul social. A propos de l'EPTNM, nous concluons que la réforme signale un renforcement du dualisme éducatif, une orientation libérale axée sur le marché et donc une précarisation de l'enseignement.

Mots-clés: Enseignement secondaire. Education professionnelle technique de niveau secondaire. Réforme de l'enseignement secondaire. Recul social. Reconfiguration de l'état. 


\section{Introdução}

nalisamos a reforma do ensino médio (EM), estabelecida pela Lei no
13.415/2017 ${ }^{1}$, especialmente, no que se refere às relações entre essa etapa e a
educação profissional técnica de nível médio (EPTNM). A Lei está abrigada por uma racionalidade maior, que alberga um conjunto de medidas, em curso ou em elaboração, cujo objetivo é reconfigurar o Estado brasileiro no sentido de torná-lo ainda "mais mínimo" no que se refere às garantias dos direitos sociais e "mais máximo" para regular os interesses do grande capital nacional e internacional, especialmente o financeiro/especulativo. Trata-se, assim, de uma nova fase de radicalização do neoliberalismo, que visa perpetrar um golpe contra a classe trabalhadora mais pobre do País, alcançada pelas políticas públicas inclusivas das duas primeiras décadas deste século.

O texto contém mais duas partes, além desta Introdução. Inicialmente, discutimos os pilares de sustentação do golpe e medidas em curso, que visam materializar sua racionalidade. Em seguida, analisamos a Lei no 13.415/2017 como parte da materialização do pensamento que preside o golpe e suas implicações para o EM e para suas relações com a EPTNM.

\section{Os pilares do golpe contra a sociedade e as medidas decorrentes}

Para situar o contexto social, político e econômico que despertou no conjunto das forças promotoras do golpe a necessidade de perpetrá-lo, recorremos às políticas sociais e econômicas desencadeadas a partir dos anos 2000.

Frigotto (2005), Boito Jr. (2003) e Paulino (2013), dentre outros, convergem em que, do ponto de vista macroeconômico, o governo Lula não mudou os fundamentos adotados por Fernando Henrique Cardoso (FHC). Todavia, há posicionamentos que identificam, nesse período, avanços e contradições na área social.

Zimmermann e Silva (2012, p. 139) partem de dados da Pesquisa Nacional por Amostra de Domicílios (PNAD) e afirmam que "em 2002, o percentual de pobres [no Brasil] era 38,3\%, diminuindo para 24,3\% em 2009". Apesar disso, o Quadro 1 mostra que não houve diminuição significativa na concentração de renda, pois o aumento dos rendimentos dos 50\% mais pobres tem menos relação com a perda de poder aquisitivo dos $10 \%$ mais ricos e mais com o achatamento do grupo intermediário. 


\section{Quadro 1 - Distribuição de renda entre os segmentos populacionais, em 2003 e em 2010}

\begin{tabular}{c|c|c}
\hline Segmento populacional & $\mathbf{2 0 0 3} \mathbf{( \% )}$ & $\mathbf{2 0 1 0}(\mathbf{\%})$ \\
\hline $50 \%$ mais pobres & 13,2 & 17,7 \\
$40 \%$ do meio & 40,7 & 37,8 \\
$10 \%$ mais ricos & 46,1 & 44,5 \\
\hline
\end{tabular}

Fonte: MOURA (2013).

O Censo ${ }^{1} 2010$ ainda evidencia superconcentração de recursos nos 1\% mais ricos, que detêm 13,8\% dos rendimentos, enquanto os $10 \%$ mais pobres ficam com 1,1\%.

Explica-se a maior diminuição da pobreza do que das desigualdades pelos conceitos de políticas públicas distributivas e redistributivas (SOUZA, 2009). As primeiras não implicam conflitos entre classes, pois os recursos destinados aos beneficiários são oriundos do aumento da capacidade arrecadadora do Estado decorrente do crescimento econômico. Já as políticas redistributivas resultam da ação do Estado no sentido de transferir renda da classe mais abastada para os pobres, incidindo diretamente nos interesses das classes. Nos governos Lula/Dilma, as políticas foram distributivas, incidentes apenas na diminuição da pobreza, o que não deixa de ser uma melhoria, embora limitada.

Entretanto, mesmo limitada a políticas distributivas, a ampliação de direitos sociais contraria pressupostos básicos da racionalidade que fundamenta o golpe, posto que sua continuidade poderia contribuir para mitigar a desigualdade social, ferindo fundamentos neoliberais. Para essa doutrina, a desigualdade é força motora da competitividade, a qual, por sua vez é essencial para o aumento da produtividade capitalista. Logo, a sociedade de mercado deve naturalizá-la, colaborando para que, na busca por uma melhor posição socioeconômica, os indivíduos entrem em competição exacerbada e sejam mais produtivos, contribuindo para a reprodução ampliada do capital.

Situado o objetivo do golpe e o contexto no qual se desenvolve, discutiremos seus pilares de sustentação e as medidas decorrentes.

O primeiro: interesses do grande capital internacional, mormente dos Estados Unidos da América (EUA). Para Pautasso e Adam (2014), as linhas gerais da política externa do governo Lula foram: aprofundamento das relações com os países emergentes Rússia, China, Índia e África do Sul, que, com o Brasil, formam os Brics; revitalização do Mercosul; retomada dos laços com a África.

Assim, a China se converteu em principal parceiro econômico do Brasil; na VI Cúpula dos Brics, se anuncia a criação do Novo Banco de Desenvolvimento e do Arranjo Continente de Reservas e "sinaliza que esta coalizão está forjando pressões e ações para alterar a distribuição de poder no mundo [... $]^{1 \prime \prime}$ (PAUTASSO e ADAM, 2014, p. 25). 
Na educação, criaram-se universidades visando fortalecer as relações com a América Latina, África e países lusófonos: Universidade Federal da Integração Latino-Americana (Unila) e Universidade Federal da Integração Luso-Afro-Brasileira (Unilab).

Isso ampliou as ações internacionais brasileiras e fortaleceu as relações Sul-Sul. Apesar de não ter deixado o eixo Norte, essa foi uma estratégia de autonomia que contrariou interesses dos EUA na América Latina. Logo, para a política externa daquele país era necessário ter no Brasil um governo confiável e sensível aos seus interesses.

Na campanha presidencial de 2014, o núcleo da crítica do Partido da Social Democracia Brasileira (PSDB) à política externa Lula/Dilma foi à

[...] branda reação brasileira à nacionalização de refinaria da Petrobrás na Bolívia por Evo Morales; a entrada da Venezuela no Mercosul; [...] a contratação de médicos estrangeiros em especial dos cubanos; [...] com relação ao plano global, perfilam as relações com os países africanos e com o Sul de modo geral [...] (LIMA; DUARTE, 2013, p. 2).

Para o PSDB, ao invés dessas alianças ideológicas, o Brasil deveria intensificar laços econômicos com países de capitalismo avançado, pois não vale à pena se "casar com pobre [...] Ficar atrelado ao Mercosul é a morte, é afundar o Brasil de vez". (THORSTENSE, 2014).

O Plano de Governo de Aécio era genérico (NEVES, 2014), mas sua visão sobre a política externa era clara:

Entre outros alinhamentos, o Brasil deixou em posição secundária a cooperação com os países desenvolvidos para priorizar as relações com nações emergentes e com os vizinhos no continente, em especial os afinados ideologicamente (NEVES, 2013).

A intensificação das relações no Hemisfério Sul e com os Brics priorizada e desenvolvida nos governos Lula/Dilma estaria fora do governo Aécio, em favor de maior aproximação com países de capitalismo avançado, especialmente os EUA: realinhamento dependente.

Ainda na esfera internacional, está o pré-sal. Sobre isso, Coelho ${ }^{4}$, ex-presidente da Petrobras, destacou como grande interesse dos EUA a tecnologia de exploração e produção em águas ultra profundas, na qual a Petrobras é líder mundial. Dominar essa tecnologia interessa para a exploração estadunidense no Golfo do México.

Matérias semelhantes ${ }^{5}$ foram veiculadas após a publicação de documentos vazados pelo ex-agente da CIA Edward Snowden, em 2013, incluindo revelações sobre interesses econômicos dos EUA em documentos sigilosos da Petrobras sobre o pré-sal.

Os EUA poderiam ter acesso mais fácil a essas informações via mudança nas regras de exploração, mas a política externa do governo Dilma era contrária à perda do domínio da Petrobras do controle da tecnologia e da operacionalização das atividades do 
pré-sal. Assim, até então, qualquer empresa vencedora de leilão deveria consociar-se com a Petrobras, sendo esta a responsável pela condução das atividades operacionais relacionadas à exploração e à produção de petróleo e gás (Lei nº 12.351/20106). Mas, o PSDB e a ampla maioria do Partido do Movimento Democrático Brasileiro (PMDB) (mesmo "estando" no governo) sempre foram favoráveis ao alinhamento com os interesses dos EUA.

Entretanto, o projeto político que abrigava essa ideia foi derrotado nas eleições de 2002, 2006, 2010 e 2014. Logo, para seus defensores era necessário aproveitar o desgaste do governo e do Partido dos Trabalhadores (PT), em função da crise econômica e da Operação Lava-jato para que o projeto derrotado nas urnas pudesse chegar ao poder sem depender dos votos do povo. Delineou-se um pilar do golpe.

Em maio de 2016, tramitava o processo de impedimento (golpe) contra Dilma, quando o senador José Serra submeteu ao Congresso Nacional (CN) Projeto de Lei (PL) visando "facultar à Petrobras o direito de preferência para atuar como operador e possuir participação mínima de 30\% (trinta por cento) nos consórcios formados para exploração de blocos licitados no regime de partilha de produção."

Como sabemos, deposto o governo, José Serra se converteu em ministro das Relações Exteriores, assumindo a função de operacionalizar a política externa de realinhamento e submissão do Brasil aos interesses do grande capital internacional.

O PL foi convertido na Lei nº 13.365/2016 e materializa a transferência do patrimônio público brasileiro ao capital internacional, comprometendo a soberania nacional (golpe em funcionamento!).

Segundo pilar: pensamento e ação das elites econômicas/grande mídia e fragmentos da classe média, refletidas no Congresso Nacional e em parte do Judiciário.

O amálgama constituído por esses grupos não forma um todo monolítico. Cada um tem seus propósitos, nem sempre convergentes. Mas, há algo que os une: medo de perda relativa de poder político, social e econômico, em razão da possibilidade de conquistas dos fragmentos mais empobrecidos da classe trabalhadora.

Assim, as conquistas desencadeadas a partir nos anos 2000 provocaram o recrudescimento do pensamento elitista-escravista que não aceita que negros (e pobres em geral), por meio das cotas, possam ocupar vagas em instituições públicas de educação superior e tecnológica, historicamente propriedade privada dos mais bem aquinhoados. Igualmente, não aceitam que empregadas domésticas tenham os mesmos direitos dos demais trabalhadores, entre outros.

As elites sociais, políticas e econômicas têm posição clara nessa disputa. Defendem a própria classe de qualquer ameaça contra a manutenção integral do projeto societário hegemônico, baseado no desenvolvimento dependente dos países de capitalismo avançado e a eles subalterno: modelo desigual e combinado, no qual os países centrais assim o 
são porque existe a periferia do capital. E, tanto no centro como na periferia, a burguesia sempre está em posição privilegiada em detrimento dos interesses dos trabalhadores ${ }^{7}$.

O fragmento da classe média já citado deu exemplos de seu modus operandi em momentos históricos nos quais demandou-se seu posicionamento diante de conflitos entre interesses de classes. Sempre se negou como classe trabalhadora, assumindo a defesa dos interesses dominantes. Foi assim que integrou as forças que desferiram o golpe de 1964. É assim que se está posicionando atualmente.

O CN é controlado por representantes dos interesses dominantes. A composição na legislatura 2015-2019 representa bem essa hegemonia (Tabela 1) (DEPARTAMENTO INTERSINDICAL DE ASSESSORIA PARLAMENTAR, 2014).

Tabela 1 - Principais grupos de interesses no CN na legislatura 2015-2019

\begin{tabular}{|c|c|c|c|}
\hline \multirow{2}{*}{ Grupo } & \multicolumn{2}{|c|}{ Parlamentares } & \multirow{2}{*}{ Interesses } \\
\hline & Senadores & Deputados & \\
\hline Empresários & 30 & 221 & Defesa do setor produtivo \\
\hline Evangélicos & 3 & 75 & $\begin{array}{l}\text { Identificado com as causas deste grupo, } \\
\text { inclusive do ponto de vista empresarial }\end{array}$ \\
\hline Ruralistas & 17 & 109 & Majoritariamente, defesa do agronegócio \\
\hline $\begin{array}{c}\text { Meios de } \\
\text { Comunicação }\end{array}$ & \multicolumn{2}{|c|}{60} & $\begin{array}{l}\text { Interesses empresariais dos } \\
\text { concessionários de rádio e/ou televisão }\end{array}$ \\
\hline $\begin{array}{l}\text { Segurança } \\
\text { pública }\end{array}$ & \multicolumn{2}{|c|}{50} & $\begin{array}{l}\text { Três grupos: legislação educativa e } \\
\text { preventiva; interesses da indústria } \\
\text { armamentista; adeptos da pena de morte, } \\
\text { redução da maioridade penal etc. (22). }\end{array}$ \\
\hline Saúde & \multicolumn{2}{|c|}{$\begin{array}{c}11 \text { (o DIAP não afirma } \\
\text { que são 11, mas só cita } 11 \\
\text { nomes) }\end{array}$} & $\begin{array}{c}\text { Três grupos: saúde pública (6); } \\
\text { interesses privados lucrativos (3); } \\
\text { defesa das santas casas/filantropia (2) }\end{array}$ \\
\hline Educação & \multicolumn{2}{|c|}{$\begin{array}{c}20 \text { (o DIAP não afirma } \\
\text { que são 20, mas só cita } 20 \\
\text { nomes) }\end{array}$} & $\begin{array}{l}\text { Três grupos: educação pública e } \\
\text { gratuita (9); organizações privadas } \\
\text { com fins lucrativos (8); instituições } \\
\text { filantrópicas e/ou vinculadas às igrejas }\end{array}$ \\
\hline
\end{tabular}

Fonte: Elaboração dos autores (DEPARTAMENTO INTERSINDICAL DE ASSESSORIA PARLAMENTAR, 2014).

Esses grupos, organizados por interesses afins, não obrigatoriamente partidários, são constituídos, majoritariamente, para defender interesses privados, haja vista os quatro primeiros que congregam a grande maioria dos parlamentares.

Os que atuam nas áreas de segurança pública, saúde e educação são minoritários e, além disso, a defesa dos interesses efetivamente públicos é minoria em cada um deles, pois os três se subdividem na defesa do público; do privado lucrativo; do privado filantrópico/religioso. 
Além disso, a Câmara Federal na atual legislatura é composta por 90\% de homens, dos quais $80 \%$ são brancos. No caso das mulheres, 10\% da Câmara, apenas 2,2\% eram negras ou pardas dentre as eleitas ${ }^{8}$.

O Judiciário também é masculino e branco. Ver Quadro 2.

\section{Quadro 2 - Composição do Poder Judiciário em 2013, por sexo e cor/raça}

\begin{tabular}{|c|c|c|c|c|c|}
\hline \multirow{2}{*}{\multicolumn{2}{|c|}{ Poder judiciário }} & \multicolumn{2}{|c|}{ Sexo (\%) } & \multicolumn{2}{|c|}{ Cor/raça $(\%)$} \\
\hline & & Homens & Mulheres & Brancos & Negros \\
\hline \multirow{3}{*}{ Juízes } & Total & 64,9 & 35,1 & 84,2 & 15,6 \\
\hline & Tribunais Superiores & 72,2 & 27,8 & 91,1 & 89,9 \\
\hline & Justiça Federal & 73,8 & 26,2 & 86,6 & 13,3 \\
\hline \multirow{3}{*}{ Servidores } & Total & 43,8 & 56,2 & 70,9 & 29,1 \\
\hline & Tribunais Superiores & 50,8 & 40,2 & 62,8 & 37,2 \\
\hline & Justiça Federal & 49,3 & 50,7 & 76 & 24 \\
\hline
\end{tabular}

Fonte: Elaboração dos autores (CONSELHO NACIONAL DE JUSTIÇA, 2014).

Esse cenário evidencia o predomínio dos grupos de interesses privados no $\mathrm{CN}$ e, no Judiciário, a hegemonia masculina e branca, acentuadamente entre os juízes dos tribunais superiores. Ou seja, nas deliberações de maior relevância, decidem os homens brancos no Poder Judiciário e, no Legislativo, os homens brancos, que representam interesses privados.

O terceiro pilar: erros do governo deposto. Não avançou nas mudanças estruturais, se envolveu em corrupção, fez alianças com a ala mais retrógrada da direita, buscou a conciliação dos irreconciliáveis interesses do capital e da classe trabalhadora.

O envolvimento em corrupção parece inegável. Portanto, não se trata de tolerá-la ou negá-la, mas evidenciar que não é esse o diferencial entre o governo deposto e as forças que o depuseram, historicamente envolvidas em corrupção. Qual o erro, então, do PT e de parte de seus membros? Não romper com essa postura histórica (GENTILI, 2016).

A corrupção não é aceitável, mas tampouco pode servir de "cortina de fumaça", pois o que está em jogo são projetos de sociedade. O projeto neodesenvolvimentista ${ }^{9}$ do governo deposto não rompeu estruturalmente com o neoliberalismo, mas viabilizou algumas conquistas de direitos. Em oposição, há o projeto das forças golpistas, cujo fim é a radicalização do neoliberalismo.

Assim, apesar dos avanços, os governos Lula/Dilma não se ocuparam de mudanças estruturais, embora houvesse possibilidades para tal. Paulino (2013) propõe: 


\begin{abstract}
juros; uma reforma tributária que estabeleça imposto fortemente progressivo de acordo com a renda e a riqueza dos contribuintes, como ocorre nos países europeus; a elevação da taxa de investimento produtivo para um mínimo de $25 \%$; a reavaliação da política cambial, de forma a proteger as empresas e os empregos dos trabalhadores do país; uma elevação significativa dos investimentos em educação, ciência e tecnologia; maior atenção básica à saúde, habitação etc. Além disso, uma Reforma Agrária verdadeira, que não destrua mais o meio ambiente, como faz o agronegócio. Estes seriam apenas alguns pontos de partida [...] para uma mudança real no país.
\end{abstract}

Essa problemática é eivada de contradições, pois essas medidas, fundamentais para avançar em um projeto contrário ao neoliberalismo, demandavam forte base de apoio parlamentar. Ao invés disso, o governo foi perdendo quadros empenhados em um projeto contra hegemônico, exatamente por não sinalizar que iria enfrentar questões estruturais.

Em nome da governabilidade construiu alianças à direita e, com base em altos índices de popularidade, foi implementando as medidas possíveis dentro do caminho trilhado.

Mas, os "aliados" sequer aderiram ao projeto, apenas o suportavam para também se aproveitar da alta popularidade do governo. Na verdade, "La derecha brasileña odia a Lula [e o PT]; lo odiaba antes de ganar las elecciones en el 2002; y lo odió durante y después de sus dos mandatos presidenciales" (GENTILI, 2016, p.77).

Quanto mais quadros comprometidos com as transformações estruturais se afastavam, mais o governo (Lula e Dilma) buscou apoio na direita conservadora que, à espreita, esperava a oportunidade para deixar de ser coadjuvante e atuar em primeira pessoa, descarregando toda sua ira reacionária contra o governo do qual fora "aliado" e os pobres que haviam conquistado uns poucos direitos.

Dilma Rousseff (DR) tinha consciência disso. Vejamos sua entrevista a Glenn Greenwald (GG):

GG: Usted dijo antes que Michel Temer está construyendo un gobierno muy conservador [...] Cunha fue retirado de la presidencia de la Cámara por corrupción. ¿Por qué usted eligió a estas dos personas como aliados tan cercanos?

DR: [...]En Brasil [...] Aumenta el número de partidos de forma sistemática y cada vez más los gobiernos necesitan de más partidos para formar una mayoría simple y una mayoría de dos tercios en el Parlamento. Hay que tener una base de alianzas. Cuanto mayor sea la base de alianzas, menos alineado política e ideológicamente esta será. Así que pasas a tener que construir alianzas muy amplias. (GENTILI, 2016, p. 17, grifo nosso).

Reflitamos sobre mais duas ações em desenvolvimento face ao golpe: Proposta de Emenda Constitucional (PEC) 287/2016² e Emenda Constitucional (EC) 95/2016. 
A Reforma da Previdência (PEC 287) coloca como condição para aposentadoria integral idade mínima de 65 anos para homens e mulheres, combinado com 49 anos de contribuição. Para alcançá-la será necessário trabalhar e contribuir para a previdência, ininterruptamente, desde os 16 até os 65 anos de idade.

Primeiramente, a medida desconsidera especificidades da mulher ao eliminar o direito de idade mínima de aposentadoria menor que a dos homens. Nega-se a dupla (até tripla) jornada feminina no mundo do trabalho e em casa, pois ainda que já exista divisão de tarefas domésticas, ela não predomina na cultura machista brasileira. Isso tudo em um país em que, apesar do aumento da inserção feminina no mundo do trabalho, seu rendimento médio mensal alcançou 74,5\% do masculino em 2014, sendo que elas tinham em média oito anos de estudo, e eles, 7,511; o índice de participação parlamentar das mulheres não alcança 10\% (GENTILI, 2016, p.31); as mulheres estão submetidas aos mais variados tipos de violência em índices alarmantes.

A PEC coloca, para homens e mulheres, a aposentadoria integral como privilégio, exatamente, na fase da vida em que se intensifica o uso de medicamentos, de alimentação especial etc. e que fisicamente se demanda por mais cuidado em função das limitações que avançam, exigindo-se aumento dos gastos. Logo, do ponto de vista dos direitos sociais, a aposentadoria integral não pode ser exceção nem privilégio, mas direito de todos.

Grave também é o fato de que a medida não considera as desigualdades regionais. Para Braga (2016), a "Reforma da Previdência é uma proposta de aprofundamento da desigualdade". Afirma ele:

Essa demografia acaba fazendo com que, por exemplo, um piso de 65 anos para aposentadoria exclua uma série de estados da federação onde a estimativa de vida da população masculina é de 65 anos ou até mesmo menos. É o caso do Maranhão e Piauí. Isso está significando um retrocesso muito grande em termos de proteção social.

Vigorando a PEC, a população masculina desses estados não alcançará o direito à aposentadoria integral. Por outro lado, o governo não incluiu na reforma os militares, o que tende a acirrar outras desigualdades (BRAGA, 2016).

Até agora tratamos da situação de quem trabalha ininterruptamente com vínculo formal desde os 16 anos de idade, mas esta não é a realidade social, pois acentuada é a informalidade. Sendo assim,

Não nos esqueçamos que hoje $44 \%$ da força de trabalho brasileira está na informalidade. Esses mecanismos que alongam o tempo contribuição tornam mais seletiva a entrada do trabalhador no sistema de aposentadoria. Isso é danoso (BRAGA, 2016). 
Quanto à EC 95, sua justificativa foi a necessidade de reduzir gastos públicos primários, face à crise orçamentária e fiscal do Estado. Esse raciocínio, aparentemente lógico, traz embutida uma racionalidade perversa, pois os recursos das áreas sociais serão limitados à variação do Índice Nacional de Preços ao Consumidor Amplo (IPCA) do ano anterior, a partir de 2018, enquanto o pagamento e amortização dos juros da dívida não serão limitados (AMARAL, 2016). Isso, em um país onde $66 \%$ das famílias tem renda mensal de até $\mathrm{R} \$ 2.034,00 ; 46 \%$ de até $\mathrm{R} \$ 1.356,00$; e apenas $1 \%$ tem rendimento mensal superior a $\mathrm{R} \$$ 13.560,00 (IBGE, 2013).

O Departamento Intersindical de Estudos e Estatísticas Econômicas (DIEESE, 2016) projetou que a redução dos investimentos em educação e em saúde, caso EC $95^{12}$ tivesse vigorado de 2002 a 2015, teria sido, respectivamente 377,7 e 295,6 bilhões de reais.

Isso inviabilizaria a criação, expansão e interiorização de universidades públicas, que vêm viabilizando o acesso de milhares estudantes ao ensino superior ${ }^{13}$, assim como da rede federal de educação profissional, que em 2002 tinha 140 unidades e chegou a 644 em 2016 ${ }^{14}$, além de outras medidas vinculadas ao direito à educação.

A seguir, analisamos a Lei $n^{0}$ 13.415/2017, fruto do contexto já discutido e que visa introduzir mudanças no EM e na EPTNM, coerente com a lógica de redução dos direitos sociais.

\section{A Lei n $^{\mathbf{0}}$ 13.415/2017 e suas implicações}

De início, o discurso oficial do governo e de apoiadores, fortemente empreendido na mídia como justificador da reforma, centra-se em crítica rasa à suposta "ineficiência e falta de flexibilidade" das redes de educação pública, atacando o EM das redes estaduais e da rede federal de educação profissional e tecnológica (EPT).

O discurso que defende a "reforma do ensino médio" urgente, por medida provisória, suprime o debate social e a manifestação democrática. Os principais argumentos justificadores são nitidamente de caráter ideológico e viés neoliberal, apoiando-se sobretudo em três aspectos: crítica ao assim denominado "currículo rígido" atual e, em consequência, na necessidade premente de sua substituição por outro "flexível, enxuto e dinâmico"; na proposição do estabelecimento de itinerários formativos diferenciados no EM, de forma a "valorizar a escolha" dos estudantes para aquele itinerário que mais os satisfaça, concedendo-lhes o chamado "protagonismo juvenil"; no estabelecimento da "escola de tempo integral".

A partir desses argumentos a reforma preconiza ações centradas na proposta de reestruturação curricular como solução para a chamada "crise do ensino médio". Ao centrar o foco na organização curricular, negligencia a questão central, que afeta a educação básica (EB) pública do País. A falta de infraestrutura que garanta o funcionamento qualificado 
das escolas públicas, destacando-se: ausência de instalações físicas adequadas, bibliotecas, laboratórios, espaços para a prática esportiva e de atividades artístico-culturais; inexistência de quadro de professores e demais trabalhadores da educação contratados por concurso público; planos de carreiras e de formação, salários dignos e condições de trabalho adequadas. Essas questões não são objeto da reforma. Logo, não se discutem as precárias condições de funcionamento das escolas e a absoluta necessidade de sua superação, indispensáveis à universalização da educação pública com qualidade socialmente referenciada.

Destacamos o caráter contraditório do discurso e da Lei. Se evidencia a impossibilidade de realização dos proclamados protagonismos juvenil e flexibilidade, pois essas precárias condições, na grande maioria das escolas, demandam amplos, vultosos e imprescindíveis investimentos. Não obstante, tal ampliação está negada por duas décadas face às consequências da EC 95, já discutida.

Advogamos que a reforma em curso agrava a fragmentação, a hierarquização social e a qualidade do EM. A "nova" organização proposta é velha na política educacional brasileira e reforça a dualidade educacional e social que caracteriza historicamente o País, potencializando a subtração de direitos da classe trabalhadora.

A reforma ataca diretamente a concepção de formação humana integral e conduz o EM a uma lógica mercadológica, francamente regressiva e em oposição ao que está disposto na atual Lei de Diretrizes e Bases da Educação Nacional, Lei 9.394/1996 (LDB), e nas Diretrizes Curriculares Nacionais para o Ensino Médio (DCNEM) vigentes.

Ao fazer política de terra arrasada sobre o EM público, o discurso oficial omite experiências positivas, em particular no ensino médio integrado à educação profissional (EMI) realizado em inúmeras escolas estaduais e na rede pública federal (Cefet, Institutos Federais, escolas vinculadas às universidades federais, Colégio Pedro II e UTFPR). Tais escolas se destacam em qualidade porque, dentre outras razões, reúnem o que em linhas anteriores denominamos condições de funcionamento necessárias, aliadas à concepção de formação humana integral, com a integração entre ciência, tecnologia, cultura e trabalho como eixos norteadores do currículo.

Essas escolas têm-se destacado positivamente em concepções e práticas educacionais, obtendo ao longo dos anos a aprovação da população quanto à qualidade da formação, fato também verificado no desempenho de seus egressos na inserção no mundo do trabalho e/ou na continuidade de estudos no ensino superior.

Recentemente, indicadores de avaliação educacional, como o Exame Nacional do Ensino Médio (Enem) e o Programa Internacional de Avaliação de Alunos (Pisa), evidenciaram que os alunos dessas escolas obtiveram médias superiores às nacionais e, em alguns casos, às de alunos de países da Organização para a Cooperação e Desenvolvimento Econômico (OCDE). Obviamente, não se trata de defender um sistema de avaliação baseado apenas nesses indicadores, aos quais temos crítica. No entanto, é 
contraditório que autoridades públicas e representantes do capital, que utilizam tais indicadores para fazer crítica à educação pública e apologia à privada, omitam dados altamente positivos alcançados por alunos de escolas públicas, a partir dos mesmos indicadores ${ }^{15}$.

O mais grave é que ao desconsiderar tais experiências, a reforma preconiza a fragmentação do EM mediante nova estruturação, conforme artigo 4o da Lei n⿳ํㅜ 13.415/2017, que altera a LDB e estabelece a organização curricular do EM por meio de itinerários formativos: "I - linguagens e suas tecnologias; II - matemática e suas tecnologias; III - ciências da natureza e suas tecnologias; IV - ciências humanas e sociais aplicadas; V formação técnica e profissional" (BRASIL, 2017).

O fatiamento em distintos itinerários ataca a concepção de EM como etapa final da $\mathrm{EB}$, afrontando a LDB e os princípios constitucionais do direito subjetivo à educação e da universalização da EB.

Com efeito, se a EB é "Direito de todos e dever do Estado" (CF 1988), se o EM é a etapa final dessa (LDB) que é obrigatória e gratuita dos 4 (quatro) aos 17 (dezessete) anos de idade, assegurada, inclusive, sua oferta gratuita para todos os que a ela não tiveram acesso na denominada "idade própria" e se os sistemas de ensino devem assegurar a universalização do ensino obrigatório (BRASIL, 2009), então a defesa da universalização da EB de qualidade, incluindo sua etapa final - o EM - é a defesa de um direito constitucional. Portanto, fazer valer esse direito, torná-lo realidade para todos não pode ser encarado como crise nem como problema, como tratam patrocinadores e defensores da reforma. É, na verdade, um bom desafio social, um passo importante e necessário no processo de travessia de uma sociedade desigual e excludente para uma igualitária em que todos estejam incluídos como cidadãos de pleno direito. Ao invés disso, a reforma promove a redução de conteúdos formativos em cada um dos itinerários formativos propostos. Ou seja, é a negação do EM como etapa final da EB.

Como crítica propositiva a essa concepção fragmentada, hierarquizada, utilitária e mercadológica, argumentamos a favor da formação humana integral. Por isso, concordamos com Frigotto, Ciavatta e Ramos (2005), quando destacam:

A ideia de formação integrada sugere superar o ser humano dividido historicamente pela divisão social do trabalho entre a ação de executar e a ação de pensar, dirigir ou planejar. Trata-se de superar a redução da preparação para o trabalho ao seu aspecto operacional, simplificado, escoimado dos conhecimentos que estão na sua gênese científico-tecnológica e na sua apropriação histórico-social. Como formação humana, o que se busca é garantir ao adolescente, ao jovem e ao adulto trabalhador o direito a uma formação completa para a leitura do mundo e para a atuação como cidadão pertencente a um país, integrado dignamente à sua sociedade política. Formação que, neste sentido, supõe a compreensão das relações sociais subjacentes a todos os fenômenos (FRIGOTTO; CIAVATTA; RAMOS, 2005, p. 85). 
Quanto à organização curricular para materializar a concepção de formação humana integral, as atuais DCNEM estabelecem que

Os eixos integradores do currículo, trabalho, ciência, tecnologia e cultura são instituídos como base da proposta e do desenvolvimento curricular no Ensino Médio de modo a inserir o contexto escolar no diálogo permanente com a necessidade de compreensão de que estes campos não se produzem independentemente da sociedade, e possuem a marca da sua condição histórico-cultural (BRASIL, 2012, p. 164).

Tal condição nos leva a considerar, na concepção de formação humana integral aqui defendida, os sujeitos do processo educacional, conforme apontado no Pacto Nacional pelo Fortalecimento do Ensino Médio:

O reconhecimento da dimensão histórica e social no qual o fazer pedagógico se realiza nos coloca diante da necessidade de que tal formação precisa estar em consonância com os sujeitos para os quais ela se destina. Nessa direção, pensamos ser adequado definir como principal referente para pensar a organização pedagógico-curricular do ensino médio as diferentes juventudes que o frequentam, suas identidades, suas culturas, suas necessidades (SIMÕES; SILVA, 2013, p. 8).

No entanto, o reconhecimento das diferentes juventudes não deve estabelecer dicotomias no processo de formação, como sinaliza a concepção dos diferentes itinerários formativos da reforma, em que se separam ciências e humanidades, trabalho e linguagem, ciências humanas e sociais e tecnologia. Ao contrário disso, consideramos que na concepção de formação humana integral,

[...] o reconhecimento desse caráter histórico-cultural da formação humana nos leva, ainda, ao encontro do avanço do conhecimento científico e tecnológico, e isso significa, em termos curriculares, partir da contextualização dos fenômenos naturais e sociais, de sua significação a partir das experiências dos sujeitos, bem como da necessidade de superação das dicotomias entre humanismo e tecnologia. Tal organização curricular pressupõe, ainda, a ausência de hierarquias entre saberes, áreas e disciplinas (SIMÕES; SILVA, 2013, p. 9).

A seguir, analisamos as concepções contidas na reforma do EM, considerando especificamente suas implicações para a EPTNM.

\section{A reforma do EM e a EPTNM}

A discussão sobre a incidência direta da Lei n⿳o 13.415/2017 na EPTNM demanda, como necessidade de contextualização e problematização, a retomada das formas de articulação da EPTNM com a EB e, em particular, com o EM, já discutidas em outros textos (FERRETTI; LIMA FILHO; GARCIA, 2016; MOURA; LIMA FILHO; SILVA, 2015; 
MOURA; LIMA FILHO, 2016, entre outros). Concordamos com o que se argumenta nesses trabalhos, os quais defendem que o ensino médio integrado (EMI) é a concepção mais consistente na perspectiva da formação humana integral, embora a legislação vigente permita as formas concomitante e subsequente.

A concepção de EMI remete ao mesmo tempo ao sentido de compreender como unidade a relação das partes no seu todo, a relação entre os diversos conhecimentos, quebrando falsas dicotomias como as que se referem ao geral e ao específico, bem como a integração entre agir e conhecer, teoria e prática.

Nesse sentido, são elucidativas as sínteses de Ciavatta (2005) e Ramos (2014) sobre o significado de formação integrada:

\footnotetext{
Ciavatta (2005), ao se propor a refletir sobre o que é ou que pode vir a ser a formação integrada pergunta: o que é integrar? A autora remete o termo, ao seu sentido de completude, de compreensão das partes no seu todo ou da unidade no diverso, o que implica tratar a educação como uma totalidade social, isto é, nas múltiplas mediações históricas que concretizam os processos educativos. No caso da formação integrada ou do ensino médio integrado ao ensino técnico, o que se quer com a concepção de educação integrada é que a educação geral se torne parte inseparável da educação profissional em todos os campos em que se dá a preparação para o trabalho: seja nos processos produtivos, seja nos processos educativos como a formação inicial, como o ensino técnico, tecnológico ou superior. Significa que buscamos enfocar o trabalho como princípio educativo, no sentido de superar a dicotomia trabalho manual / trabalho intelectual, de incorporar a dimensão intelectual ao trabalho produtivo, de formar trabalhadores capazes de atuar como dirigentes e cidadãos (RAMOS, 2014, p. 24).
}

Entretanto, a análise do quadro nacional do EM evidencia que a oferta do EMI é reduzida e centralizada na rede federal e em algumas estaduais, embora destaquemos seu crescimento no último decênio (MOURA; LIMA FILHO, 2016). Com efeito, nosso argumento é em defesa da ampliação da oferta do EMI em todo o território nacional, nas redes públicas de ensino. Reiteramos como relevante a significativa expansão da rede federal de EPT em termos quantitativos e qualitativos, dada a descentralização mediante capilarização para além das capitais e grandes cidades e a diversificação do público atendido. Na perspectiva do fortalecimento do EMI e da ampliação nacional de sua oferta, é fundamental que esse movimento de expansão seja consolidado e a oferta ampliada, também, na esfera pública estadual.

Contrariamente, a Lei nº 13.415/2017 encaminha o EM para concepção distinta da formação humana integral e do EMI, como veremos ao analisar quatro de seus aspectos, relacionados ao itinerário "formação técnica e profissional": estabelecimento dos itinerários formativos específicos; profissionalização precoce, com foco no mercado e a certificação intermediária; professores; relação público x privado. 
Itinerários formativos específicos e "formação técnica e profissional"

Reafirmamos que a centralidade da reforma está na constituição de cinco itinerários formativos, sendo inclusive o mais divulgado como elemento de propaganda ideológica a flexibilidade do currículo e do protagonismo conferido aos estudantes pela possibilidade de escolha de um dos itinerários. No entanto, por trás desse argumento reside a concepção mais regressiva da reforma, evidenciando-se o aligeiramento do EM pela redução curricular; a perda da concepção de EM como etapa final da EB, dado que a ideia de itinerários específicos é frontalmente contrária à concepção das DCNEM, que em seu art. 14 preconizam que “O Ensino Médio, etapa final da Educação Básica, concebida como conjunto orgânico, sequencial e articulado, deve assegurar sua função formativa para todos os estudantes ..." (BRASIL, 2012, grifo nosso).

Por fim, o estabelecimento do itinerário formativo denominado "formação técnica e profissional" revela forte retomada da categoria dualidade estrutural, que historicamente tem se manifestado na educação nacional, como reflexo de uma sociedade cindida em classes, que destina aos trabalhadores mais empobrecidos processos educacionais pobres, caracterizados pela redução e instrumentalidade de conteúdos direcionados para aspectos meramente do fazer, em detrimento dos conhecimentos de base científico-tecnológica e sócio histórica. Tudo isso em contradição com a totalidade social, integralidade e interdisciplinaridade, que caracterizam a produção e a apropriação dos conhecimentos e o processo educacional.

\section{Profissionalização precoce e certificação intermediária}

A dualidade estrutural referida no tópico anterior fica mais evidenciada quando se analisam pontos da Lei n⿳⺈ 13.415/2017 especificamente dirigidos a esse itinerário, elucidando o seu caráter de aligeiramento e operacionalidade. Vejamos, por exemplo, o $\S$ $6^{\circ}$ do artigo $4^{\text {․ }}$.

\footnotetext{
$\S 6^{0}$. A critério dos sistemas de ensino, a oferta de formação com ênfase técnica e profissional considerará:

I - a inclusão de vivências práticas de trabalho no setor produtivo ou em ambientes de simulação, estabelecendo parcerias e fazendo uso, quando aplicável, de instrumentos estabelecidos pela legislação sobre aprendizagem profissional;

II - a possibilidade de concessão de certificados intermediários de qualificação para o trabalho, quando a formação for estruturada e organizada em etapas com terminalidade (BRASIL, 2017, grifo nosso).
}

A inclusão de vivências práticas, as parcerias, os certificados intermediários de qualificação e a atribuição de etapas de terminalidade estão presentes na legislação, 
indicando a intenção de fazer mais prático, operacional e rápido o processo de trânsito para o mercado de trabalho dos sujeitos que cursarão o itinerário "formação técnica e profissional". Ressaltamos que a profissionalização precoce, parcial, fragmentada e com terminalidade intermediária no processo educacional adicionalmente dificultam aos egressos desse itinerário o acesso ao ensino superior, já que deles serão subtraídos conteúdos de formação geral das ciências naturais, humanas e sociais.

\section{Os professores da "formação técnica e profissional"}

A análise da Lei n⿳⼈ㅗ 13.415/2017 permite identificar direcionamento para a desvalorização, a desqualificação e o ataque à formação e profissionalidade dos docentes da EB de modo geral, e, em particular, do EM, sendo mais grave o tratamento dado aos professores do itinerário "formação técnica e profissional" . O artigo $6^{0}$ dessa Lei estabelece que profissionais com notório saber podem ministrar conteúdos de áreas afins à sua formação ou experiência profissional exclusivamente nesse itinerário (BRASIL, 2017, grifo nosso).

Assim, por um lado a reforma induz à desqualificação da atividade docente e, por outro, encaminha a precarização geral das condições de trabalho desses profissionais, seja dos licenciados ou dos ditos com notório saber. Para os últimos, a docência frequentemente se apresenta como uma atividade complementar, acumulada com outros vínculos, o que significa intensificação de trabalho, com a diversidade e simultaneidade de contratos temporários, e vulneráveis, com consequências prejudiciais à qualidade do processo educativo.

Nesse sentido, inferimos que a Lei, ao estabelecer o notório saber, baseado na experiência profissional específica (não docente) como requisito suficiente para o exercício da docência na EPTNM, reforça aspectos meramente práticos e de treinamento na formação destinada aos sujeitos da classe trabalhadora, reiterando a dualidade e a precariedade histórico-estrutural que caracterizam a educação dirigida aos trabalhadores no capitalismo como um processo de formação limitada (SHIROMA; LIMA FILHO, 2011), para o qual a atividade docente - como corolário - é reduzida a mera instrução.

\section{A relação público x privado na formação técnica e profissional}

O já mencionado artigo $4^{\circ}$. da Lei n⿳ํㅜㄹ 13.415/2017 introduz alterações no artigo 36 da LDB, dentre as quais as do $\S^{0} 11$, dispondo que os sistemas de ensino poderão reconhecer competências e firmar convênios com instituições de educação a distância com notório reconhecimento para a realização de diversas atividades da formação técnica e profissional, dentre elas cursos de educação a distância (grifos nossos). Abrem-se possibilidades para a realização das chamadas parcerias, que na prática funcionam como meio de transferir recursos públicos, do Fundo de Manutenção e Desenvolvimento da 
Educação Básica e de Valorização dos Profissionais da Educação (Fundeb) e outras fontes, para a iniciativa privada. Não é sem razão que figuram entre os principais apoiadores da reforma a Confederação Nacional da Indústria, o Sistema S e fundações de bancos e empresas privadas.

Além das questões mencionadas nos aspectos já analisados, a reforma do EM, no que concerne à EPTNM, apresenta um imbróglio organizacional, posto que seguem vigentes o capítulo da LDB relativo à EPT e todo o ordenamento complementar de Diretrizes Curriculares e outros, que trazem orientações distintas às apresentadas pela reforma.

Em síntese e a modo de conclusão, além da desorganização do ordenamento legal e do não-reconhecimento das experiências positivas da EPTNM, como o EMI, as principais implicações da reforma são o recrudescimento da dualidade educacional, do fortalecimento da orientação mercadológica e da formação precoce na educação profissional, da precarização e desvalorização da docência e do incentivo à privatização. Tal reforma traz efeitos sociais deletérios, aos quais se impõe a necessidade de resistência implacável, pois sua implantação representará a perda de direitos e perspectivas de uma formação humana integral para adolescentes, jovens e adultos da classe trabalhadora que frequentam a escola pública de EM e de EPTNM.

\section{Recebido em 02/06/2017 e aprovado em 06/06/2017}

\section{Notas}

1 Decorrente da MP 746/2016.

2 Divulgado pelo Instituto Brasileiro de Geografia e Estatística (IBGE).

3 Declaração de Fortaleza, emitida pelos Brics. Disponível em: <http://brics.itamaraty.gov.br/pt_br/imprensa/comunicados-de-imprensa/215-vi-cupula-do-brics-declaracao-de-fortaleza>.

4 Em entrevista concedida a Leandro Cipriano no Portal O Globo. Disponível em: <http://www.agenciacti. com.br/index.php?option=com_content\&view=article\&id=8873:especialistas-temem-perdas-tecnologicas-com-projeto-que-altera-marco-legal-do-pre-sal>. Acesso em: 05 jan. 2017.

5 Disponível em: <http://www.bbc.com/portuguese/noticias/2013/09/130908_eua_snowden_petrobras_dilma_mm; http://www.cartacapital.com.br/politica/petrobras-tambem-foi-espionada-pelos-eua-9881.html, dentre outros>. Acesso em: 07 jan. 2017.

6 Esta Lei foi alterada pela Lei no ${ }^{0} 13.365 / 2016$.

7 Ver Lowy (1995).

8 Disponível em: <http://www2.camara.leg.br/camaranoticias/noticias/POLITICA/475684-HOMENS-BRANCOS-REPRESENTAM-71-DOS-ELEITOS-PARA-A-CAMARA.html>. Acesso em: 07 jan. 2017.

9 Para aprofundamento ver Ramos (2016). 
10 Outras medidas seguem a mesma lógica. Escolhemos essas, face à repercussão sobre toda a sociedade. Pertence a esse conjunto mais abrangente, a Reforma Trabalhista, mas não trataremos dela face à limitação de espaço.

11 Disponível em: <http://www.valor.com.br/brasil/4315176/ibgepnad-mulheres-recebem-745-do-que-ganham-os-homens>. Acesso em: 06 jan. 2017.

12 À época do estudo a PEC 241 não havia sido aprovada, de modo o texto a ela se refere. Ressaltamos que não houve mudança na conversão da PEC em EC.

13 Dentre elas, a Unila e a Unilab já mencionadas, além da Fundação Universidade Federal do Pampa (Unipampa); Universidade Federal do Cariri (UFCA); Universidade Federal do Oeste da Bahia (Ufob); Universidade Federal do Sul e Sudeste do Pará (Unifeespa); Universidade Federal do Recôncavo da Bahia (UFRB); Universidade Federal do Sul da Bahia (Ufesba); Universidade Federal dos Vales do Jequitinhonha e Mucuri (UFVJM); Universidade Federal Rural do Semi-Árido (Ufersa-RN), entre outras.

14 Disponível em: <http://redefederal.mec.gov.br/expansao-da-rede-federal>. Acesso em: 05 set. 2016.

15 "Depois de "equivocadamente" deixar os institutos federais de fora da divulgação de resultados do Enem, o MEC minimiza o bom desempenho das escolas públicas federais em outra avaliação: o Programa Internacional de Avaliação de Estudantes (Pisa), da Organização para Cooperação e Desenvolvimento Econômico (OCDE), em que o Brasil ficou em $63^{\circ}$ lugar entre 72 países. Em meio ao lamentável resultado as escolas federais obtiveram ótimos índices. Se a rede federal de ensino fosse um país, em Ciências - a matéria escolhida como foco da análise desta edição - o "país das federais" ficaria em 11o lugar no ranking internacional, um ponto acima da tida como exemplar Coreia do Sul, que teve uma média de 516 pontos. Apesar disso, o ministro Mendonça Filho (Educação) só conseguiu discursar sobre o "fracasso retumbante" da educação brasileira, passando ao largo - pela segunda vez - dos bons índices apresentados pelas federais" (BORGES, 2016).

\section{Referências}

AMARAL, N. C. PEC 241/55: a "morte" do PNE (2014-2024) e o poder de diminuição dos recursos educacionais. RBPAE, v. 32, n. 3, p. 653-673, set./dez. 2016.

BOITO Jr., A. A hegemonia liberal do governo Lula. Crítica marxista, Rio de Janeiro, n. 17, 2003.

BORGES, H. Estudantes federais têm desempenho coreano em Ciências, mas MEC ignora. The Intercept, 8 dez. 2016. Disponível em: <https://theintercept.com/2016/12/08/estudantes-federais-temdesempenho-coreano-em-ciencias-mas-mec-ignora/>. Acesso em: 10 fev. 2017.

BRAGA, R. Entrevista: "Reforma da Previdência é uma proposta de aprofundamento da desigualdade". Carta Capital, dez. 2016.

BRASIL. Lei $n^{\circ}$ 13.415, de 16 de fevereiro de 2017. Altera a Lei nº 9.394, de 20 de dezembro. Diário Oficial [da] República Federativa do Brasil, Brasília, 2017. Disponível em: <www.planalto.gov.br>. Acesso em: 20 fev. 2017.

BRASIL. Emenda Constitucional nº 59, de 11 de novembro de 2009. Dá nova redação aos incisos I e VII do art. 208, de forma a prever a obrigatoriedade do ensino de quatro a dezessete anos e adota outras providências. Diário Oficial [da] República Federativa do Brasil, Brasília, 2009. Disponível em: <www.planalto.gov.br>. Acesso em: 20 fev. 2017.

BRASIL. Diretrizes curriculares nacionais para o EM. Resolução CNE/CEB nº 02/2012. Diário Oficial [da] República Federativa do Brasil, Brasília, 31 jan. 2012, seção 1, p. 20. 
BRASIL. Lei no 9.394, de 20 de dezembro de 1996. Estabelece as diretrizes e bases da educação nacional. Diário Oficial [da] República Federativa do Brasil, Brasília, 1996. Disponível em: <www. planalto.gov.br>. Acesso em: 25 abr. 2010.

CIAVATTA, M. A formação integrada: a escola e o trabalho como lugares

de memória e de identidade. In: RAMOS, Marise; FRIGOTTO, G.; CIAVATTA, M. (Orgs.). Ensino Médio Integrado: Concepção e Contradições. São Paulo: Cortez, 2005; pp. 83-105.

CONSELHO NACIONAL DE JUSTIÇA. Censo do Poder Judiciário. Brasília, 2014.

DEPARTAMENTO INTERSINDICAL DE ASSESSORIA PARLAMENTAR. Radiografia do novo congresso: Legislatura 2015-2019. Brasília, 2014. 164 p.

FERRETTI, C. J.; LIMA FILHO, D. L.; GARCIA, S. R. O. Educação Profissional. In: SILVA, M. R.; GARCIA, S. R. O. (Org.). Formação de professores do ensino médio: modalidades. Curitiba: UFPR, 2015. v. 1, p. 7-17.

FRIGOTTO, G. O Brasil e a política econômico-social: entre o medo e a esperança. Observatório Social da América Latina, Buenos Aires, v. 14, p. 95-104, 2005.

FRIGOTTO, G.; CIAVATTA, M.; RAMOS, M. Ensino médio integrado: concepção e contradição. 1. ed. São Paulo: Cortez, 2005. 176p.

GENTILI, P. Brasil: estado de excepción. In: ANDERSON, P. et al. Golpe en Brasil: genealogía de una farsa. Buenos Aires: Fundación Octubre; UMET, 2016. p. 27-33.

IBGE. Pesquisa Nacional por Amostra de Domicílios - 2013. Brasília, 2013.

LIMA, M.; DUARTE, R. Diplomacia presidencial e politização da política externa: uma comparação dos governos FHC e Lula. Observatório On-line, v. 8, n. 9, p. 1-24, 2013.

LOWY, M. Teoria do desenvolvimento desigual e combinado. Actuel Marx, n. 18, 1995.

MOURA, D. H. Mudanças na sociedade brasileira dos anos 2000 limitadas pela hegemonia do neoliberalismo: implicações para o trabalho e para a educação. In: Dante Henrique Moura. (Org.).

Produção de conhecimento, políticas públicas e formação docente em educação profissional. 1ed.

Campinas/SP: Mercado de letras, 2013, v. 1, p. 109-140.

MOURA, D. H.; LIMA FILHO, D. L. Os diferentes e desiguais ensinos médios no Brasil: o que fazem os que trabalham durante esta etapa educacional. In: CARVALHÊDO, J. L. P.; CARVALHO, M. V. C.; ARAUJO, F. A. M. (Orgs.). Produção do conhecimento na pós-graduação em educação no nordeste do Brasil: realidades e possibilidades. Teresina: EDUFPI, 2016. v. 1, p. 151-187.

MOURA, D. H.; LIMA FILHO, D. L.; SILVA, M. R. Politecnia e formação integrada: confrontos conceituais, projetos políticos e contradições históricas da educação brasileira. Revista Brasileira de Educação, v. 20, n. 63, out./dez. 2015.

NEVES, A. Plano de governo Aécio Neves - PSDB. [S. 1. : s. n.], 2014. Disponível em <http://contee. org.br/contee/wp-content/uploads/2014/10/Plano-de-governo_aecio1.pdf>. Acesso em: 03 jan. 2017.

NEVES, A. “(Des)alinhamento". Portal UOL. 02 set. 2013. Disponível em: <http://mais. uol.com.br/view/m71emkrqkizd/desalinhamento--artigo-do-senador-aecio-neves04020C9A3868D4B14326?types=A\&>. Acesso em: 03 jan. 2017.

PAULINO, R. Desregulamentação, desindustrialização e reconcentração de renda na crise dos EUA. Economia Política do Desenvolvimento, v. 5, p. 77-106, 2013. 
PAUTASSO, D.; ADAM, G. P. A política da política externa brasileira: novamente entre autonomia e alinhamento na eleição de 2014. Revista Conjuntura Austral, v. 5, n. 25, ago./set. 2014.

RAMOS, M. N. História e política da educação profissional. Curitiba: Instituto Federal do Paraná, 2014. (Coleção formação pedagógica; v. 5).

RAMOS, M. N. Projetos societários em disputa no Brasil contemporâneo: a universalização da educação básica e a educação profissional. In: MOURA, D. H. (Org.). Educação profissional: desafios teórico-metodológicos e políticas públicas. Natal: IFRN, 2016. p. 117-140.

SHIROMA, E. O.; LIMA FILHO, D. L. Trabalho docente na Educação Profissional e Tecnológica e no PROEJA. Educação \& Sociedade, v. 32, p. 725-743, 2011.

SIMÕES, C. A., SILVA, M. R. Formação de professores do ensino médio, etapa I - caderno III: o currículo do ensino médio, seu sujeito e o desafio da formação humana integral. SEB/MEC. Curitiba, 2013.

SOUZA, L. M. Políticas públicas: introdução às atividades e análise. Natal: EDUFRN, 2009.

THORSTENSE, V. Entrevista: “Ficar atrelado ao Mercosul é afundar o Brasil”. Carta Capital, 19 maio 2014.

ZIMMERMANN, C. R.; SILVA, M. C. Combate à fome e à miséria no governo Lula: garantia do direito à alimentação? Revista Espaço Acadêmico, Maringá, n. 129, 2012. 